ARTÍCULO

\title{
Latinoamérica y las disputas por la hegemonía en el campo educativo: trayectorias teórico-históricas en la circulación norte-sur
}

\author{
Sebastián Neut Aguayo' \\ Pablo Neut Aguayo" (D
}

\section{RESUMEN}

El texto presenta una lectura de conjunto de las disputas por la hegemonía educativa durante los siglos XIX y XX, analizando la circulación de ideas y materializaciones históricas a que dieron curso en el escenario de las relaciones Norte-Sur. Al respecto, nos enfocamos en la trayectoria latinoamericana, particularizando en el caso chileno. El recorrido propuesto permitirá avizorar los modos predominantes que ha adquirido la disputa por la hegemonía en el campo educativo, evidenciando algunos de sus límites y realzando posibles aprendizajes que estas experiencias pueden eventualmente proporcionar a quienes se encuentran comprometidos actualmente con la transformación educativa y social.

\section{PALABRAS CLAVE}

América Latina; Chile; contrahegemonía; educación; hegemonía. 


\title{
LATIN AMERICA AND THE DISPUTES OVER HEGEMONY IN THE EDUCATIONAL FIELD: THEORETICAL AND HISTORICAL TRAJECTORIES IN THE NORTH-SOUTH CIRCULATION
}

\author{
ABSTRACT \\ committed to educational and social transformation. \\ KEYWORDS \\ Latin America; Chile; counter-hegemony; education; hegemony.
}

The text presents an overall reading of educational hegemony disputes during the $19^{\text {th }}$ and $20^{\text {th }}$ centuries, analyzing the circulation of ideas and the historical materializations to which they gave rise in the scenario of North-South relations. In this regard, this text is focused on the Latin American trajectory, especially in the Chilean case. The proposed path will allow to glimpse the predominant modes that the dispute for hegemony in the educational field has acquired, showing some of its limits and highlighting potential learnings that these experiences could eventually provide for those who are currently

\section{AMÉRICA LATINA E AS DISPUTAS POR HEGEMONIA NO CAMPO EDUCACIONAL: TRAJETÓRIAS TEÓRICO- HISTÓRICAS NA CIRCULAÇÃO NORTE-SUL}

\section{RESUMO}

O texto apresenta uma visão geral das disputas sobre hegemonia educacional durante os séculos XIX e XX, analisando a circulação de ideias e materializações históricas ocorridas no cenário das relações Norte-Sul. Nesse sentido, focamos na trajetória latino-americana, principalmente no caso chileno. $\mathrm{O}$ percurso proposto nos permitirá vislumbrar os modos predominantes que adquiriu a disputa pela hegemonia no campo educacional mostrando alguns de seus limites e destacando possíveis lições que essas experiências podem eventualmente proporcionar àqueles que estão hoje em dia comprometidos com a transformação educacional e social.

América Latina; Chile; contra-hegemonia; educação; hegemonia. 


\section{INTRODUCCIÓN}

La importancia en América Latina de los actores educativos en la puesta en cuestión del orden educacional, y con ello social, no es nueva. Rastros de ello se encuentran en los ecos educacionales de la revolución mexicana, el movimiento de reforma universitario cordobés de 1918, la acción de la Asociación General de Profesores de Chile de la década de 1920, la escuela-ayllú boliviana de la década de 1930, los movimientos de reforma universitaria de las décadas de 1960 y 1970 , las políticas educativas del gobierno de la Unidad Popular chilena, el movimiento de educadores populares de la triunfante revolución nicaragüense de 1979 y las escuelas zapatistas de fin de siglo, entre otros. Estos no solo tuvieron incidencia en sus propios países, sino que levantaron la esperanza de cambios, reformas, e incluso revoluciones, que alentaban a las comunidades regionales.

Con relación a los vínculos entre educación y hegemonía en América Latina durante el siglo XX, la mayoría de los trabajos realizados se centran en el estudio de casos específicos (Reyes, 2014; Baronnet, 2015; Donoso-Romo y Contreras-Mühlenbrock, 2017). Como contraparte, otros analizan procesos regionales, como el desarrollo de la educación popular, subordinando la dimensión local a la realidad histórica más amplia (Mejía, 2014; Puiggrós, 2016; Jara, 2020). En el presente texto proponemos una vía intermedia para el estudio de los procesos educativos regionales, integrando de manera ensayística el análisis de una situación local - la educacional chilena - en las trayectorias teórico-históricas que modularon las luchas por la hegemonía y contrahegemonía a nivel regional y global. En este contexto, el objetivo es analizar el desarrollo de las ideas educativas hegemónicas y contrahegemónicas que predominaron en el paisaje histórico del siglo XIX y, particularmente, del siglo XX en América Latina, y su relación con lo que sucedía en el campo teórico y de políticas oficiales en los países de capitalismo avanzado. Se utiliza a modo de ejemplo el caso chileno. Por una parte, este país, en tanto que participante del contexto regional, ilustra en su desarrollo la historia misma del subcontinente. Por otra, su desarrollo histórico constituyó, en momentos importantes, una expresión singular y que hizo las veces de "faro" para el resto de la región. Con ello, pondremos atención en la particularidad del caso expuesto, pero insertándolo, en cuanto sea posible, en la trama más amplia de la que fue componente y parte.

Con este ejercicio, lo que se pretende es generar una comprensión de los procesos de disputa por la hegemonía en el campo educativo bajo una perspectiva que permita articular y entrecruzar actores, contextos, escenarios y propuestas, precisamente porque aquella pluralidad es la que ha fundado el dinamismo del campo. Del mismo modo, la relevancia de este tipo de aproximación es que puede idealmente proporcionar insumos teórico-políticos o aprendizajes históricos para el desarrollo de propuestas actuales que tiendan a la transformación educativa y social.

Se trata de una invitación para indagar en los lenguajes educacionales en perspectiva histórica, o lo que para la situación educacional Basil Bernstein denomina discurso pedagógico, el cual "engloba y combina dos discursos: un discurso técnico que vehicula destrezas de distintos tipos y las relaciones que las unen y un discurso de orden social... (que remite) al discurso moral que crea orden, relaciones 
e identidad" (Bernstein, 1996, p. 62). Ahora bien, en la medida en que las sociedades y los grupos que las componen presentan diferentes proyectos educacionales, la construcción, difusión y mantención de todo discurso pedagógico hegemónico supone colaboración, pero también conflicto con otras propuestas educacionales y sus respectivos discursos pedagógicos. Estas pueden, como muchas veces ha ocurrido, tomar un camino contrahegemónico, es decir, disputar el sentido global de la versión pedagógica predominante (Apple, 1979; Da Silva, 1999).

A nivel metodológico, se desarrolla una estrategia que interrelaciona el conocimiento ya obtenido sobre las políticas y teorías hegemónicas y contrahegemónicas, sobre todo en lo que a países del "Norte" refiere, con el cotejo y la revisión extensa de fuentes primarias que permiten observar de primera mano el desarrollo de las estrategias propuestas desde el "Sur". Como se puede inferir a partir de las aclaraciones previas, el texto tiene la intención de ensayar una narrativa de conjunto y en perspectiva histórica de los complejos procesos teóricos y políticos que han configurado el campo educativo, particularmente el de la educación formal y escolar.

Para ello, presentamos un recorrido histórico de los siglos XIX y XX en un doble registro. Por una parte, proponemos una organización temática y temporal de los discursos pedagógicos presentes en los países centrales o de capitalismo avanzado. Por otra, analizamos las experiencias históricas desarrolladas en el "Sur", centrándonos particularmente en el caso chileno. La intención no es, por supuesto, insinuar que los países del "Sur" actúan como meros receptores de las ideas dominantes creadas en el "Norte". Tampoco, por tanto, sostener un privilegio ex cathedra de este último en la estructuración de los modelos educativos. Por el contrario, lo que se pretende, como señalamos, es enfatizar en el carácter dinámico e interrelacional de los procesos de disputa por la hegemonía en el campo educativo.

\section{HEGEMONÍA Y CONTRAHEGEMONÍA EDUCACIONAL A FINES DEL SIGLO XIX Y PRINCIPIOS DEL XX}

Los sistemas educativos nacionales se originaron y "sistematizaron" (Müller, Ringer y Simon, 1987) entre fines del siglo XIX y comienzos del siguiente. Estos correspondieron a estructuras político-administrativas, enmarcadas en el espacio jurídico y cultural del Estado-nación, y generaron un modo específico de transmisión cultural hacia las nuevas generaciones, bajo la presunción de que cualquier otro mecanismo de socialización en la dimensión pública de la niñez y la juventud resultaba ilegítimo (Viñao, 2006).

Dichos sistemas fueron fundamentados en la necesidad de generar cohesión y, a la vez, segmentación, al entramado social advenido en el contexto de profundización capitalista. El afán cohesivo se tradujo en el intento de integración de toda la niñez a la escuela primaria nacional, aduciendo la necesidad de "moralizar", alfabetizar y generar una identificación con la patria. La segmentación se produjo de manera "vertical" con la creación de los niveles secundario y universitario, cuyo cupo estaba reservado para los sectores dirigentes (Müller, Ringer y Simon, 1987). 
Este modelo fue respaldado a nivel intelectual en la teoría sociológica de Durkheim. Para este, cohesión y estratificación también serían objetivos prioritarios de la educación. Respecto del primero, planteaba que "no existe ningún pueblo en el que no exista cierto número ideas, de sentimientos y de prácticas que la educación tiene que inculcar a todos los niños indistintamente, sea cual fuere la categoría social a la que pertenecen" (Durkheim, 1976, p. 97). Sin embargo, en algún punto, esta debía segmentarse, como un requisito de supervivencia de las sociedades modernas. De acá que "la educación, a partir de cierta edad, no puede ya seguir siendo la misma para todos los sujetos a los que es aplicada" (Durkheim, 1976, p. 95).

Así, tanto a nivel político como ideológico y "académico", la perspectiva hegemónica adquirió un cariz conservador. La educación, particularmente primaria, debía transmitir la cultura de la sociedad entendiendo que ello constituía un requisito para la preservación de su unidad como colectivo. El nivel superior, por su parte, quedaría restringido a la elite, asegurando con ello su posición de regencia social.

Prontamente, el modelo descrito fue puesto en cuestión en los "países centrales”. Allí surgieron movimientos reformistas que seguían el ideario de pedagogos como Maria Montessori en Italia, John Dewey en Estados Unidos u Ovide Decroly en Bélgica. Estos impugnaron la concepción de que el sujeto del aprendizaje constituía una "tabula rasa", incapaz de producir un conocimiento autónomo a partir de su propia experimentación con el entorno circundante. Estas tradiciones pedagógicas fueron tardíamente reunidas bajo el rótulo de la "Escuela Nueva". Aunque en su versión "oficial", sobre todo en lo que concierne a Dewey, se vinculó el proceso educacional con la participación democrática liberal, sus derivaciones políticas e ideológicas fueron más amplias, con lecturas que iban desde la pedagogía de tintes católicos hasta otras de corte revolucionario (Popkewitz, 2005).

Pero no solo los pedagogos cuestionaron el modelo educativo dominante. No fueron pocos los trabajadores que practicaron la autoeducación (Rancière, 2010) o intelectuales que impugnaron la misma institución escolar, tanto en su declarado afán cohesivo como en el estratificador. En ambos casos, adujeron que tales fundamentos eran modos de inculcación de un orden social inequitativo y que sus formas didácticas promovían la adhesión/obediencia del estudiante al status quo. En esta dirección destacó la experiencia de la Escuela Moderna levantada por el ácrata catalán Francisco Ferrer (2014).

\section{DISPUTAS POR LA HEGEMONÍA EN AMÉRICA LATINA Y CHILE DURANTE LA PRIMERA MITAD DEL SIGLO XX}

El caso latinoamericano muestra una situación particular dentro del campo del "Sur" global. A diferencia de los sistemas educativos africanos y de gran parte de los asiáticos - surgidos tras los procesos de descolonización en la medianía del siglo $\mathrm{XX}^{1}$ — , estos fueron promovidos por los Estados-nacionales desde el siglo XIX, constituyendo estructuras altamente centralizadas. Fue lo que se conoció como Estado-docente (Newland, 1994).

1 Un caso paradigmático fue el de Congo, cuyo sistema educacional recayó en instituciones coloniales belgas y, fundamentalmente, misiones católicas (Depaepe, 2019). 
Con todo, la acción de este resultaba deficitaria a comienzos del siglo XX, fundamentalmente a nivel de masificación de la escuela primaria. Como consecuencia, surgieron múltiples movimientos ciudadanos que tendían a suplir tales déficits, a la vez que presionaban al Estado para que diese mayor atención a la niñez y adultez desescolarizadas. Fueron los casos, por ejemplo, de las sociedades populares de educación en Argentina (Carli, 1991) y las Escuelas Nocturnas para Obreros chilenas (Reyes-Jedlicki, 2007). En una dirección diferente, socialistas y, sobre todo, anarquistas, crearon instancias educativas que impugnaban a la escuela tradicional. En Chile, por ejemplo, surgieron las "escuelas libertarias", influenciadas por la experiencia de Ferrer en España (Lagos, 2013). Al carácter supletorio de las Escuelas Nocturnas y el afán paraestatal de las propuestas ácratas, debemos sumar otro proyecto histórico pedagógico de amplio impacto regional. Nos referimos al surgimiento de la Asociación General de Profesores de Chile en 1922. Esta generó un relato de fuerte connotación sociopolítica y de crítica al sistema escolar vigente. La Asociación se definió como un organismo gremial y técnico, impugnador del Estado docente y sus modalidades didácticas, apolítico en términos de militancia partidaria y comprometida con una transformación socioeconómica estructural (Reyes, 2014). Se trató de un movimiento que, a partir de la acción propiamente pedagógica y social, presionó la política con el objetivo de instaurar un modelo educativo orientado por una relectura revolucionaria de los presupuestos de la Escuela Nueva (diferente en consecuencia a la desarrollada en el "Norte").

En el contexto latinoamericano de la primera mitad del siglo XX, constituyó una de las más importantes iniciativas del movimiento social por impulsar una política estatal global en clave revolucionaria. El intelectual y político peruano José Carlos Mariátegui afirmaba que "la Asociación General de Profesores de Chile representa el más interesante y considerable movimiento de maestros de toda América" (Mariátegui, 1929), mientras que el pedagogo suizo Adolphe Ferrière planteaba que "los maestros de escuela chilenos... fueron efectivamente los primeros, no limitándose a exponer teorías... que se lanzaron a la práctica, sin circunscribir el movimiento a unas cuantas escuelas privilegiadas, porque ambicionaban transformar la educación pública de su nación" (Ferrière, 1932, p. 6).

En su desarrollo se encargaron de exponer reiteradamente que su norte era "luchar incansablemente por la reconstrucción total del sistema educacional" (Nuevos Rumbos², 15 ago. 1924, p. 5 apud Reyes, 2014, p. 92), y que para lograrlo pretendían instalar una propuesta educacional propia e integral, la que debía ser asumida como política desde el Estado. Su acción tuvo tal incidencia pública que, ad portas de la promulgación de una nueva Constitución política, el presidente Arturo Alessandri los acusó de que "han constituido un Estado dentro del Estado" (Nuevos Rumbos, 2 jun. 1925 apud Reyes, 2014, p. 78).

Consideraban que el Estado-docente estaba corroído por intereses políticos que atentaban en contra del desempeño propiamente "técnico", que en la época era sinónimo del saber que emergía de los propios docentes, concebidos como los

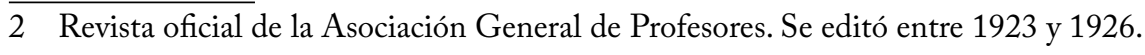


expertos en la materia. Por otra parte, acusaban de excesivo intelectualismo y saber memorístico al promovido a nivel oficial, e influenciados por la Escuela Nueva propusieron que la escuela

tendría el mínimo de salas, solo las indispensables para ciertas clases que requieren escritorios. La verdadera enseñanza se daría en los talleres y en los campos de cultivo y de crianza, la verdadera escuela sería la que más se acerque a la naturaleza, la que tuviera el cielo por techo y el césped y la arena por pavimento, el horizonte por ventana y flores, los frutos y los insectos, y los árboles por libros de estudio (Revista de Educación Primaria, 1928 apud Reyes, 2014, p. 144).

Su visión respecto de la educación entroncaba con una utopía social radical. Por una parte, la educación debía confluir en la industrialización del país. Según tal ideario "faltan las industrias... Es necesario mirar lo que producen nuestros ríos, campos, mares y montañas para desarrollar las industrias inherentes a esos productos. Para esto, nuestras escuelas deben estar dotadas de personas entendidas en dichas materias" (Nuevos rumbos, 15 mayo 1925 apud Reyes, 2014, p. 95).

Por otra, imbuidos de una visión gremial-productivista, planteaban que en el futuro no existirían "los que nada producen, como los militares, los frailes, los abogados, los jueces, los policías y los políticos” (Nuevos Rumbos, 17 dic. 1924 apud Reyes, 2014, p. 93). Los profesores, por el contrario, eran concebidos como productores no materiales al servicio de la sociedad. En el fondo, estas propuestas se sustentaban en la idea de que la educación estaba habilitada para llevar a cabo - y debía comprometerse con - la transformación social. Como señala Reyes (2014, p. 98), "dentro de la concepción del movimiento de maestros primarios, la versión local de la Nueva Escuela constituía el verdadero motor del cambio social”.

En un contexto de convulsión social y política, el gobierno autoritario del militar Ibáñez llamó a las autoridades de la Asociación para que implementaran su programa a nivel estatal. De esta manera, en 1927 se inició "la primera reforma integral en la historia de la educación chilena" (Núñez,1987, p. 83). El experimento duró poco y al año siguiente sus autoridades fueron depuestas e incluso deportadas y sus miembros reprimidos. El alcance de reinvención social no estaba en línea con lo que un gobierno autoritario esperaba. Se daba inicio así a una "contrarreforma".

De hecho, durante las décadas de 1930 y 1950, los gobiernos de América Latina se nutrieron de un lenguaje nacionalista y, como iniciativas originariamente estatales, llevaron a cabo reformas parciales a sus sistemas educacionales (Bruno-Jofré,2016), sin un carácter rupturista. De esta manera, se fue consolidando el Estado-docente. Paralelamente, en el Norte se verificaba un "reencantamiento" en torno al rol de la educación.

\section{RECONFIGURACIÓN DEL DISCURSO PEDAGÓGICO HEGEMÓNICO A MEDIADOS DEL SIGLO XX}

Hacia la medianía del siglo XX, en el "Norte"la educación adquirió un estatus privilegiado como campo de acción estatal. Como consecuencia del surgimiento del Estado de bienestar, los países desarrollados empezaron a concebir la educación 
como un derecho social. Asimismo, el nuevo contexto de Guerra Fría y de "revolución tecnológica" los condujo a enfatizar en la formación de mano de obra y profesionales cualificados para la aplicación del conocimiento científico en los procesos productivos. En esta orientación subyacía una idea propia de los sectores reformistas pero asimilada bajo una interpretación tecnoeconómica, a saber, que la educación tenía la potencialidad de potenciar el progreso material y social (Bonal, 1998).

Esta situación fue concomitante con la creencia de que la administración pública y la producción podían resultar objeto de mayor "eficiencia" a partir del uso del conocimiento científico (Popkewitz, 1994). Por ello, las ciencias sociales representaron un soporte legitimador de las decisiones políticas y su conocimiento experto constituyó el fundamento "científico" para los proyectos de "ingeniería social" liderados por el Estado. En efecto, el saber propiamente pedagógico fue subordinado por aquel que otras disciplinas, especialmente la sociología y la economía, lograban ofrecer.

Estas disciplinas servirán de insumo primario para la consolidación del nuevo discurso hegemónico educacional. Importantes resultaron las obras del sociólogo Talcott Parsons y de los economistas Theodore Schultz y Gary Becker. El primero estableció una relación de homologación entre la escuela y la sociedad — refinando el análisis funcionalista inaugurado por Durkheim — en su obra "La clase como sistema social" de 1959. Los últimos, con publicaciones de 1960 y 1964 respectivamente, desarrollaron la teoría del capital humano. Según esta, la educación constituía una forma de capital cuya acumulación e incremento redituaría en una futura rentabilidad. Así, la educación, y su afán "cualificador", adquirirá un carácter instrumental y orientado fundamentalmente al ámbito laboral.

Para sus propulsores, la aplicación de estos presupuestos posibilitaría el despliegue de un ciclo de crecimiento ininterrumpido, y en regiones como la latinoamericana, representaría una alternativa para la superación del subdesarrollo, manteniendo incuestionada la matriz capitalista. No resulta extraño que tal teoría fuese adoptada para planificar y financiar los sistemas educativos por parte de muchos Estados y de organismos internacionales como la OCDE, el Banco Mundial y el Fondo Monetario Internacional.

La influencia de la teoría del capital humano se vio reforzada en su maridaje con una propuesta particular de la justicia social, la de la meritocracia. Esta adquirió preminencia en el pensamiento social y en la conciencia de los ciudadanos de los países de capitalismo avanzado en la medianía del siglo. Como señala Bonal (1998, p. 19),

es a partir de la segunda mitad del siglo XX, en plena consolidación de los estados de bienestar, cuando la meritocracia deja de ser solamente un principio de legitimación ideológica para adquirir una dimensión hegemónica, es decir, cuando la población de las sociedades avanzadas cree realmente en ella.

Con este nuevo "ideal" se comenzó a concebir la desigualdad social como una consecuencia derivada del esfuerzo individual y se estableció el mecanismo legítimo para producirla: la educación (Dubet, 2011). Lógicamente, desde la perspectiva meritocrática resultaba ominosa la preservación de sistemas escolares de explícito espíritu segregacionista. Por ello, los gobiernos europeos de la época tendieron a generar reformas educacionales que promovían la integración - horizontal y vertical - de los estudiantes (Fernández Enguita, 1989). 
De esta manera, mientras la teoría del capital humano redujo el debate a cuestiones de relación entre educación, mercado laboral y productividad, el ideal meritocrático lo hizo en torno al tema de la igualdad de acceso. Así, los ropajes de la "ciencia" entrelazados con los de la "justicia social" — liberal —, obturaron temporalmente la discusión en torno a la posibilidad de pedagogías alternativas.

Sin embargo, ya durante la década de 1960 el "modelo educativo meritocrático" demostraba sus límites, evidenciando el masivo fracaso escolar de colectividades sociales que habían sido integradas al sistema escolar. Esta realidad estimuló la investigación y el impulso de políticas reformistas dentro del propio paradigma liberal-funcionalista. Así, en 1966 - y por encargo del gobierno de Estados Unidos - el icónico Informe Coleman concluyó que las desigualdades educativas se explicaban fundamentalmente por los "déficits culturales" de las familias.

La constatación de que el mérito no lograba hacerse efectivo (ni en movilidad social, ni como "inversión" en capital humano) a pesar de las reformas implementadas, generó el escenario para el surgimiento de teorías de crítica radical al modelo. A comienzos de la década de 1970 emergieron fuertes embestidas teóricas hacia los procesos de escolarización. En países del "Norte", especialmente Francia, se denunció a la institución educativa como un "aparato" difusor de la "ideología burguesa" (Althusser, 1974) ${ }^{3}$, se develó la "naturalización" de la cultura dominante como cultura "objetiva" y su posterior imposición hacia los sectores subalternos a manera de una "violencia simbólica" (Bourdieu y Passeron, 1995) escolar como un conjunto de redes educacionales que imitaban la división del trabajo (Baudelot y Establet, 1976)5. Otros, en Estados Unidos, por ejemplo, pusieron el foco en las relaciones sociales de la escuela. Particular impacto generó la publicación "La instrucción escolar en la América capitalista" (Bowles y Gintis, 1976), texto que intentó demostrar la "correspondencia" que existía entre las relaciones establecidas en la escuela y aquellas desarrolladas en el ámbito de la producción laboral.

En conjunto, estos esfuerzos - de fuerte impronta teórica antes que política - fueron aglutinados en torno a la tesis de la reproducción. En efecto, tuviera ella un carácter económico (Bowles y Gintis), ideológico (Althusser) o cultural (Bourdieu y Passeron), estas interpretaciones coincidieron en señalar a la escuela como un instrumento de perpetuación de las estructuras sociales de dominación. La tesis reproduccionista será ampliamente adoptada, aunque recontextualizada, en la Latinoamérica setentista.

\section{RECONTEXTUALIZACIÓN DE LA EDUCACIÓN MERITOCRÁTICA Y LA TESIS DE LA REPRODUCCIÓN EN EL “SUR” DURANTE LAS DÉCADAS DE 1960 Y 1970}

América Latina quedó ubicada como zona de influencia "occidental" dentro del escenario de "Guerra Fría”. En la región, la teoría del capital humano y el ideal merito-

3 Primera edición de 1970.

4 Primera edición de 1970.

5 Primera edición de 1971. 
crático fueron 'traducidos' en clave modernizadora o desarrollista, influidas por la acción de agencias vinculadas a Estados Unidos - especialmente la Agencia Internacional para el Desarrollo. En efecto, desde este gobierno y sus ramas "científicas" se difundió la idea de que el subcontinente debía salir del subdesarrollo (entre otras cosas, como medida disuasoria del comunismo). Con todo, ello no podría hacerse al modo de los países "desarrollados", ya que, se aducía,la región no tenía el equipamiento material ni la capacidad humana para enfrentar exitosamente tal desafío. Este, en consecuencia, debía ser inducido con apoyo externo y, con particular énfasis, mediante la reestructuración de sus sistemas educativos. Ello quedó claramente de manifiesto con la creación de la Alianza para el Progreso en 1961 (Puiggrós, 2015). En adelante, y bajo su influjo se implementaron una serie de reformas basadas en el paradigma del "planeamiento de la educación". De acuerdo con este, la educación debía ser diseñada centralmente, destinada a toda la población escolar y sometida a rigurosos procesos de control técnico y científico. Así la década de 1960 fue considerada una “época dorada' de los organismos internacionales dedicados a la educación que, apoyados en el consenso alrededor de la necesidad del planeamiento, ejercerían una profunda influencia en el redireccionamiento de las políticas educativas en la región" (Suasnábar, 2013, p. 106).

En Chile, y con fuerza desde la asunción de un gobierno reformista (democratacristiano) en 1964, se impuso la tarea del "planeamiento" del sistema educacional. La teoría del capital humano y el ideal meritocrático hicieron eco en tierra latinoamericana y especialmente chilena. Mario Leyton, uno de los inspiradores de aquella reforma, expresaba la "absorción" de tales discursos. Por una parte, planteaba que "los economistas concluyeron que el alto nivel de desarrollo económico de ciertos países y a la inversa, el bajo standard de otros, presentaban estrecha correlación con los niveles medios de educación respectivos" (Leyton, 1975, p. 3) ${ }^{6}$.

Por otra parte, señalaba que "la educación es un factor de movilidad social. Este poder se acrecienta en la medida en que se aproximan los vínculos entre la realidad escolar y la de la sociedad misma" (Leyton, 1975, p. 51). En efecto, el diagnóstico presentado por el equipo reformista partía de la constatación de que "la educación no estaba actuando como canal de movilidad social y que, por el contrario, retardaba y dificultaba el cambio social, con grande peligro para la vida democrática" (Núñez, 1990, p. 70). En una novedad respecto del "Norte", se aducía que, en sociedades fuertemente desiguales pero con amplias demandas democratizadoras, dicha movilidad "meritocrática" permitiría legitimar el orden social y político.

$\mathrm{El}$ paradigma modernizador que incentivó la reforma educativa del gobierno democratacristiano prontamente fue desbordado desde la izquierda, que criticó su carácter funcional respecto del modelo capitalista. En tal crítica resultaba identificable la nítida impronta de las teorías reproduccionistas. A nivel académico su uso fue explícito, particularmente en su versión althusseriana. El argentino Tomás Vasconi, en 1973 y bajo el alero del Centro de Estudios Socioeconómicos dependiente de la Universidad de Chile, escribió un artículo que se convertiría en un texto icónico de la traducción latinoamericanista de la reproducción: "Contra la escuela”.Planteó que los objetivos del

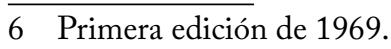


"Aparato Educativo" en la sociedad capitalista eran la capacitación de mano de obra y la imposición y difusión de la ideología y cultura dominantes. Como novedad respecto de las versiones europeas, sumó una idea propia de la "teoría de la dependencia", al postular que el campo educativo regional chocaba con las lógicas inherentes a burguesías rentistas, las que ni siquiera invertirían en el campo educacional en miras a generar reformas basadas en la teoría del "capital humano" (Vasconi, 1973). En un registro similar se situó el trabajo de la argentina Susana Barco y su "Antididáctica"(Barco,1973). En este, vinculó la dependencia con una forma de enseñar verticalista y autoritaria. Haciendo una crítica al "taxonomismo" de los seguidores de Bloom, planteó que ello derivaba en una "penetración ideológica" cuyo objetivo era domesticar a la niñez latinoamericana.

Desde la arena propiamente política, la izquierda chilena también criticó su carácter funcional respecto del modelo capitalista. Lo inédito del caso chileno es que tales tesis adquirieron un carácter "oficial" al asumir el gobierno de Salvador Allende y la Unidad Popular en 1970. La experiencia de esta coalición de izquierda tuvo una enorme influencia continental.

Respecto de las políticas educacionales del gobierno previo se afirmaba:

La reforma educacional de la democracia cristiana, en lo político, tuvo como objetivo consolidar la base de sustentación del régimen capitalista... En lo económico, respondía a los intereses de los empresarios nacionales y extranjeros que reclamaban niveles más altos de eficiencia en la producción para elevar sus utilidades y competir en el mercado internacional; en lo social, se pretendió crear ilusiones respecto de las ventajas de una sociedad comunitaria, de claro signo paternalista. (Ministerio de Educación, 1971a, p. 76)

Así también, entre los aportes que el ministerio de educación daba para la preparación del Congreso Nacional de Educación, instancia convocada entre otros por el Sindicato Único de Trabajadores de la Educación, la Central Unitaria de Trabajadores y el mismo gobierno con el objetivo de delinear una política educacional de carácter nacional, se afirmaba que la escuela chilena "ha permitido, por un lado, la formación de una élite que se reserva el privilegio de actuar en los planos dirigentes y, por otro, de una gran masa cuya tarea se desarrolla a través del trabajo manual y de incipiente nivel tecnológico"(Ministerio de Educación, 1971a, p. 72). De esta manera, desde el oficialismo se afirmaba que la escuela tenía por objeto replicar y asegurar a nivel instruccional la división social del trabajo ya existente a nivel infraestructural.

Lo paradojal fue que el gobierno y sus bases de soporte incubaban un proyecto educativo revolucionario ${ }^{7}$ al mismo tiempo que debían administrar un sistema educacional al que se atribuía un carácter reproductivo, y el que no podía ser cambiado sino a remolque de lo que ocurría a nivel económico y social. Al respecto, en 1970 el subsecretario de Educación, Waldo Suárez Sambont (1970, p. 5), afirmaba que "entre estructura social y sistema educativo hay una relación y

7 El carácter rupturista de la Unidad Popular bajo una mirada de conjunto a la situación educativa de la segunda mitad del siglo en María Oliva (2010). 
dependencia insoslayables. La primera determina irremediablemente a la segunda, y nunca, históricamente, ha sido posible invertir el proceso". En alguna medida, tal paradigma operó en un sentido inmovilizador ${ }^{8}$. Sería por ello que "diversos sectores de maestros han intentado modificar el sistema educacional, creyendo honestamente que con más y mejores escuelas se transformaría la sociedad. Sus ensayos siempre han terminado en fracasos prácticos o en resultados muy limitados" (Ministerio de Educación, 1971b, p. 173), cuestión explicable por

la imposibilidad de realizar transformaciones sustanciales de la educación en el cuadro de las estructuras capitalistas; la necesidad de iniciar las transformaciones revolucionarias de la sociedad, hacia el socialismo, [aparece] como requisito para democratizar y desarrollar realmente la educación. (Ministerio de Educación, 1971b, p. 173)

Muchos actores educativos participaban de este imaginario que fundía, por un lado, la lógica interpretativa de las teorías de la reproducción y, por otro, una perspectiva economicista que subordinaba la posibilidad de transformación educativa al cambio en las estructuras socioeconómicas. Lo atestigua la opinión de una profesora de ciencias sociales, quien sostenía que "no hay cambios revolucionarios en ningún establecimiento de la enseñanza científico-humanista, porque no hay cambios revolucionarios en la sociedad [...], mientras el socialismo no desplace al individualismo, no habrá transformación estructural del liceo"(Concha, 1971, p. 67).

Como contraparte, existía en el oficialismo una visión de la creación de políticas educacionales que las hacía descansar en las decisiones de toda la comunidad educativa, lo que suponía un reposicionamiento del saber de sus actores, desplazados previamente por los “cientistas sociales". En 1970 el ministro de Educación Mario Astorga explicaba que

corresponde a los trabajadores de la Educación y a los sectores de la comunidad, directa o indirectamente involucrados en el proceso educacional chileno, definir la "política educacional" que nuestro país debe sustentar en esta nueva y expresiva forma de vida que hemos determinado consolidar. (Astorga, 1970, p. 2)

En términos concretos esta nueva política educativa tenía por objetivo, en palabras de Allende, terminar con el carácter "clasista, y por lo mismo, discriminatorio e injusto" (Allende, 1972, p. 29) del sistema formativo chileno. Al respecto, el eje articulador del currículum debía empezar a ser el sistema de producción. En tal línea, el gobierno y su ministerio de educación proponían que "el trabajo productivo estará presente a lo largo y ancho de todo el proceso educativo [...] estará presente en todos los niveles, en todas las áreas y asignaturas, a través de múltiples enfoques, formas, contenidos y actividades" (Ministerio de Educación, 1971a, p. 80).

8 Un funcionario estadounidense que trabajaba en el ministerio de educación junto con otros connacionales, recuerda que "queríamos explicar por qué la política educacional parecía tener tan poca prioridad en un nuevo Estado socialista, ya que esta parecía ser una anomalía histórica" (Farrell, 1986, p. vii, traducción propia). 
El énfasis productivista de esta propuesta, sin embargo, se instalaba en las antípodas de la teoría del capital humano, pues, estaba orientado en una perspectiva del trabajador como eje de la prosperidad social y no como mero factor de producción. Se respondía, por tanto, a un ideal de sociedad donde el trabajo se instalaba como soporte del bienestar colectivo y espacio privilegiado para la solidaridad social. En este sentido, "la nueva educación incorporará la solidaridad, la conciencia y la responsabilidad social al primer lugar de sus objetivos, para erradicar el individualismo estéril y egoísta, para reemplazar el espíritu competitivo por el espíritu de superación colectiva" (Ministerio de Educación, 1971a, p. 80).

En alguna medida, la versión "reproductivista" junto con la "democrática de base" se suturaban a nivel ideológico en la idea de que la educación debía acompañar la construcción de la sociedad socialista, cuestión que adquiría fisonomía en la formación del Hombre Nuevo. "Necesitamos formar al Hombre Nuevo para la sociedad socialista” (Núñez,1970, p.10), expresaba el superintendente de educación. Y desde el ministerio refrendaban esta postura: "la formación de este Hombre Nuevo es la gran tarea social que vamos a cumplir antes que asome el siglo XXI con sus prodigios. Para ello, necesitamos una nueva educación" (Ministerio de Educación, 1971b, p. 174). Este era entendido en los siguientes términos:

- Solidario y comprometido ideológica y prácticamente con su pueblo y con la Humanidad que lucha y se libera;

- Consciente y capaz de formarse una concepción científica del universo y de la sociedad;

- Consecuente, crítico y responsable;

- Formado en el trabajo productivo material como mecanismo básico de humanización;

- Abierto al goce y creación de los valores estéticos;

- Armónicamente desarrollado desde el punto de vista psicobiológico. (Ministerio de Educación, 1971b, p. 174)

Con esta propuesta de transformación integral, las perspectivas críticas y contrahegemónicas lograban un espacio para su materialización - a modo de proyecto global - desde el poder del Estado, cuestión inédita en aquellos países del "Norte" que habían generado la primera versión de las teorías reproduccionistas. Sin embargo, esta oportunidad original y única fue abortada por el golpe de Estado de 1973.

\section{HEGEMONÍA Y CONTRAHEGEMONÍA EDUCACIONAL A PARTIR DE LA DÉCADA DE 1970}

Desde la década de 1970 la reflexión académica sufrió un pronunciado "giro teórico”, basado en la crisis del paradigma dominante que había dado sustento epistemológico a las teorías de la reproducción: el estructuralismo (Dosse, 2004). Ya fuese desde la perspectiva genealógica foucaultiana que pretendía deshacerse de las "teorías envolventes y globales" (Foucault, 1997, p. 20), desde la crítica filosófica 
que desafiaba toda posición fundante de los metarrelatos (Derrida, 1989) ${ }^{9}$, desde una tradición marxista que alegaba por un mayor interés en la dimensión cultural (Williams, 2003) o desde la antropología que intentaba dotar de mayor historicidad y dinamismo a la vida cotidiana $(\mathrm{Geertz}, 2003)^{10}$, lo cierto es que la pretensión sistemática y totalizante propia del estructuralismo empezó a ser disputada por otra más centrada en las agencialidades y el análisis empírico de situaciones concretas.

En este contexto, las críticas a las teorías de la reproducción no tardaron en surgir. El excesivo "determinismo" de sus propuestas, y el economicismo de las versiones marxistas ortodoxas, fueron dardos constantes. Desde las propias posiciones críticas, los esfuerzos por superar tales límites dieron lugar al desarrollo de nuevos núcleos problemáticos en torno al discurso pedagógico dominante. Estos asumieron dos direcciones.

En primer lugar, habilitó el ingreso a lo que empezó a ser conocido como la “caja negra” (Lacey, 1970) ${ }^{11}$ de la escolarización. En la práctica, antes que enfocar el análisis en la estructura de los resultados educativos - tal como sucedía en la tesis reproduccionista -, esta nueva orientación impulsará el estudio de las prácticas y procesos que se despliegan al interior de las escuelas y de los procesos formativos. E1 acceso a la "caja negra" demostró que en las aulas no se producía una interiorización aproblemática de la cultura hegemónica, sino que procesos de disputa entre la cultura escolar y la que portaban los sectores subordinados de la sociedad. Desde el punto de vista etnográfico, el libro "Aprendiendo a trabajar" (Willis, 1977) constituyó un texto inaugural. En semejante línea, surgió la noción "currículum oculto", entendido como "aquellas normas, creencias y valores no declarados, implantados y transmitidos a los alumnos por medio de reglas subyacentes que estructuran las rutinas y las relaciones sociales en la escuela y en la vida en las aulas" (Giroux, 2004, p. 72) ${ }^{12}$.

Complementariamente, en Inglaterra, surgió la denominada Nueva Sociología de la Educación (Young, 1971; Bernstein, 1989¹3), mientras que en Norteamérica se desarrolló la sociología del currículum (Apple, 1979). Estas comprendieron la dimensión educativa - y especialmente la del currículum - como un "campo" de disputa. Tales enfoques tuvieron la cualidad de enfatizar la dimensión del poder en la lucha por la hegemonía educacional y, con ello, aportar en la superación de la imagen de completa "dominación" que preconizaban las teorías de la reproducción.

9 Originalmente una conferencia de 1966.

10 Versión original de 1973.

11 El concepto "black box of schooling" fue acunado por C. Lacey en 1970. Con este, quiso indicar que las metodologías cuantitativas y el análisis de las escuelas tipo "entradas y salidas" no tenían en cuenta las causas del deteriorado rendimiento de los estudiantes de la clase trabajadora en Manchester. A partir de este momento el concepto se difundió y adquirió un desarrollo propio que se dirigió en varios sentidos, pero siempre intentando escudriñar lo que sucede al interior del aula en su dimensión sociocultural (González, 2013). A nivel de la historia de la educación su desarrollo es más tardío (Depaepe y Simon, 1995; Braster, Grosvenor y Del Pozo, 2011).

12 Jackson (1992) lo mencionó por primera vez en 1968 en una perspectiva que los teóricos críticos denominaron como "conservadora". Posteriormente este fue adaptado desde posiciones críticas o "radicales" (Giroux, 1983).

13 Versión original de 1971. 
En este punto surgió la segunda dirección aludida. Ambas tradiciones señalaban que, si bien existían profundos condicionamientos económicos, la cuestión definitoria del campo educativo se jugaba en pugnas de poder y su capacidad para instalar "patrones de cultura" (Williams, 2003, p. 127) o un "discurso regulativo" (Bernstein, 1996, p. 82) a los escolares. Dicho en otras palabras, su capacidad para constituirse en un discurso pedagógico hegemónico (Apple, 1979).

El desplazamiento de la dimensión económica por la del poder - y su relación con la cultura - tuvo una implicancia directa respecto de las formas en que era concebida la posibilidad de llevar a cabo transformaciones educacionales y sociales. En efecto, lejos del inmovilismo que destilaba en las teorías reproduccionistas, en esta nueva aproximación la educación adquiere centralidad en los procesos de transformación social, particularmente mediante la pugna por la imposición - o la impugnación - de los patrones culturales dominantes. Con estos lineamientos, las perspectivas contrahegemónicas generaron una nueva aproximación crítica sustentada en la noción de resistencia.

El nuevo enfoque no solo reivindicó la agencia de los actores educativos para contestar la imposición cultural, sino que también estimuló el compromiso de sus propulsores con proyectos emancipatorios (Giroux, 1983; McLaren, 1984), al modo del intelectual orgánico propuesto por Gramsci. Durante la década de 1980, por tanto, las teorías de la resistencia se instalaron como la matriz interpretativa de lo que se denominó como la "pedagogía crítica". Desde entonces, tales resistencias fueron comprendidas asumiendo, aunque no de manera excluyente, a la clase social como eje del discurso y la práctica contrahegemónica.

De manera paralela, en Latinoamérica era publicado el influyente libro "Pedagogía del oprimido" (Freire, 1970) ${ }^{14}$. Respecto de las relaciones que existen entre la propuesta de este libro inaugural y la realidad sociocultural chilena, el propio intelectual brasileño (exiliado en Chile entre 1964 y 1969) afirmó:

El tema surgió al recordar mi relación con los oprimidos de Brasil y la diferencia que encontré con la historia cultural de la sociedad chilena. Cuanto más me internaba en el mundo del campesino chileno, cuanto más lo escuchaba hablar, más evidente me resultaba la relación entre opresor y oprimido, la conciencia opresora y la conciencia oprimida [...] Pedagogía del oprimido era un intento por comprender esa relación. (Freire, 2004, p. 94)

Desde su publicación Freire se transformó en el pedagogo del "Sur" que ha tenido mayor influencia en el origen y desarrollo de la pedagogía crítica y en el mentor (y amigo) de sus propulsores en el "Norte". En su texto, condena la tradicional "educación bancaria", en la que el estudiante es concebido como un 'depósito' a ser rellenado de conocimientos que lo enajenarían de su propio saber y cultura y, a diferencia de la "aséptico" lenguaje académico de sus correligionarios del "Norte", Freire habla de "esperanza", "fe en los hombres", "amor" y "humildad"

14 La versión original fue escrita en portugués en Chile hacia 1968. 
(Da Silva, 1999) ${ }^{15}$. Así, frente al determinismo inmovilizante de las interpretaciones reproduccionistas, el pedagogo brasileño restituirá la agencialidad de los sujetos y su posibilidad de transformar las tradicionales formas educativas.

\section{LA EDUCACIÓN LATINOAMERICANA Y CHILENA EN DICTADURA. ENTRE LA REPRESIÓN, EL NEOLIBERALISMO Y LA “EDUCACIÓN POPULAR”}

Aunque con antecedentes en Brasil (golpe de Estado de 1964), los intentos de impugnación contrahegemónica en el campo educativo latinoamericano sufrieron un duro revés al instalarse desde principios de la década siguiente una serie de dictaduras amparadas en el ideario de la Doctrina de Seguridad Nacional ${ }^{16}$ y de proyectos neoliberalizantes.

En el caso chileno, el término traumático de la experiencia de la Unidad Popular resultó importante a nivel continental. Chile era considerado hasta ese momento un 'paraguas' intelectual dentro de la región, en virtud de la mantención de un sistema liberal democrático y el asentamiento en el país de importantes centros de pensamiento, como el Instituto Latinoamericano de Planificación Económica y Social (ILPES) y la Facultad Latinoamericana de Ciencias Sociales (FLACSO). Freire y Vasconi, por ejemplo, habían llegado al país como exiliados de las dictaduras en sus propias naciones. El golpe de Estado, en consecuencia, constituyó un momento de inflexión, por la diáspora intelectual que produjo, y por el cuestionamiento respecto del tipo de régimen político y proyecto educativo que se pretendía instalar (Suasnábar, 2013, p. 43).

En este contexto se produjo una crítica del paradigma educacional sostenido hasta ese momento y la apertura a la creación de otro diferente. Según la reflexión de aquel momento, la adopción acrítica del predominante paradigma althusseriano (y la lógica mecánica de las teorías de la reproducción), había llevado al descuido de la dimensión cultural (Bruno-Jofré, 2016), en el entendido de que dentro de esta se jugaba también el juego por el poder (Puiggrós, 2016). En el relevo de esta dimensión, las referencias a Gramsci y su noción de hegemonía, y a la pedagogía freiriana resultaron centrales.

Del mismo modo se produjo una crítica a lo que fue considerado como un uso abusivo de la noción de "clase social", asociada al trabajador asalariado, depositario excluyente de los procesos emancipatorios. Para desligarse de la "estrechez" de tal noción, fueron recuperadas las más inclusivas de "pueblo" y "popular".

15 Iván Illich, sacerdote austriaco radicado en México, tuvo una posición más ecléctica. En el libro "La sociedad desescolarizada" (Illich, 1971) postuló que el reforzamiento de la escolarización era una forma de incremento del control social sobre quienes empezaban a ser 'objetos de escolaridad'. A mayor escolarización, mayor pérdida de autonomía en el nombre de la propia liberación de los "escolarizados".

16 El teórico brasileño de la DSN, J. A. Amaral Gurgel, planteaba que la educación correspondía al principal factor dentro de los cuatro que componen el Poder Nacional (los otros tres son el político, el económico y el militar) (Núñez,1984). De acá se puede comprender la feroz represión que sufrieron escuelas y universidades, como ejemplifican los casos chileno (Neut Aguayo, Neut Aguayo y Neut Aguayo, 2020) y argentino (Seia, 2020). 
Estas permitían incluir a grupos históricamente marginados que no calzaban con la clásica figura del trabajador (como mujeres, pobladores y, en lo que a nosotros compete, niños y adolescentes). En síntesis, se trataba de escudriñar y promover una "cultura popular" (Bruno-Jofré, 2016), lo que dio origen a un nuevo paradigma contrahegemónico regional: la "educación popular" (García-Huidobro y Martinic, 1980). Este fue un proyecto que entrelazó fuertemente teoría y práctica en el campo educativo, y que tuvo gran desarrollo en Latinoamérica, particularmente en Chile y Brasil (Suasnábar, 2013), además de la Nicaragua sandinista (Bruno-Jofré, 2016).

En el campo teórico, hubo dos ramificaciones. Algunos sostuvieron que el descuido de las subjetividades habría impedido ver las potencialidades que la democracia liberal - aunque en sus versiones nacional-populares, fundamentalmente - tenía para la disputa por la hegemonía en sus sistemas educativos formales. Para la intelectual y política argentina Adriana Puiggrós, por ejemplo,

La educación tiene capacidad de incidir en los procesos de transformación social, pues participa en las luchas por la constitución de la hegemonía. Las demandas y propuestas pedagógicas se producen dentro y no fuera de ese espacio... El proceso educativo, cargado del significado político-pedagógico que Antonio Gramsci le adjudicó, participa en la creación, recreación y transformación de los sujetos sociales, y los sujetos históricos se constituyen dentro de una lucha que tiene un hondo significado político-pedagógico, y que simultáneamente va constituyendo los discursos pedagógicos. (Puiggrós, 2016, p. 27) ${ }^{17}$

Otros, por el contrario, y centralmente en el caso chileno de la primera mitad de la década de 1980, sostuvieron que la dimensión cultural resultaba central en la configuración de un proyecto contrahegemónico, pero que en el campo educacional debía plantearse autónomo respecto del Estado y su cultura educativa autoritaria (García-Huidobro y Martinic, 1980). En esta dirección, desde fines de la década de 1970 ONG's vinculadas a educación, fundamentalmente el Centro de Investigación y Desarrollo de la Educación (CIDE) y el Programa Interdisciplinario de Investigaciones en Educación (PIIE), reforzaron su ámbito de acción en la educación no formal (Neut Aguayo, 2018). A comienzos de la década siguiente se sumaron otras, como Educación y Comunicaciones (ECO).

La "educación popular" fue entendida "como una práctica educativa que se inscribe al interior de un proceso más amplio, que busca que los sectores populares se constituyan en un sujeto político consciente y organizado"(García-Huidobro y Martinic, 1980, p. 1). A la vez, se la concebía como contraria a la impuesta por el Estado. Pero a diferencia de lo que ocurría en el paradigma pre-1973, ahora se consideró a la cultura un aspecto central en los procesos emancipatorios. $\mathrm{Al}$ respecto, planteaban, recurriendo a la noción de hegemonía gramsciana, que "los sectores dominantes no sólo son dominantes sino que llegan a ser también dirigentes. Vale decir, los grupos sociales dominantes logran una supremacía también en el plano cultural, intelectual

17 Primera edición de 1984. 
y moral" (García-Huidobro y Martinic, 1980, p. 3). Si el dominio de clase se ejerce también mediante las formas de transmisión cultural, eso "permite valorar ampliamente la educación popular como acción política. La búsqueda de una sociedad distinta no puede ya ser pensada como un mero cambio económico, por importante que sea este cambio, ni como un puro cambio de manos del aparato estatal coercitivo. Las exigencias y necesidades que surgen en el terreno económico deben encontrar su expresión eficiente en la creación de una nueva voluntad colectiva, capaz de actuar y de pensar la sociedad de modo distinto"(García-Huidobro y Martinic, 1980, p. 3).

En tal sentido, se argüía que, aunque la cultura de los sectores subordinados expresaba "una larga historia de dominación, también cultural" (García-Huidobro y Martinic, 1980, p. 4), en su propio interior — a diferencia de la figura del 'Hombre Nuevo' que operó siempre en la dimensión del futuro y como consecuencia de los cambios económicos - se encontraban ya contenidos algunos elementos emancipatorios. La educación popular debía, en consecuencia, dotarlos de organicidad, "depurarlos" de su herencia de dominación y proyectarlos. Para ello, retomaron la noción freiriana de la concientización "según la cual la criticidad aparece ligada a la realidad y posibilidad de participar en forma autónoma e independiente en la producción de la historia" (García-Huidobro y Martinic, 1980, p. 14).

Desde 1984, en un contexto en el que las fuerzas políticas habían adquirido un mayor peso dentro del debate público y se hacían ver los efectos de la implementación del proyecto neoliberal en educación, la preocupación por la educación popular empezó a ser desplazada en favor del sistema formal. $Y$ aunque se mantuvo como práctica difundida, su fuerza teórica decreció de manera exponencial. En este caso, a diferencia de lo sucedido con los movimientos contrahegemónicos antes estudiados, no fue la represión lo que desactivó al movimiento, sino una mayor preocupación por la recuperación de la democracia y por el lugar de la educación formal en la misma. De hecho, algunos de sus propulsores posteriormente se insertaron en los círculos políticos y académicos oficialistas y, desde allí, participaron en las reformas educativas tras la recuperación de la democracia en 1990.

El siglo XX se cerró con una serie de reformas educativas de corte neoliberal en la región. Chile también ocupó un rol central en este proceso de instauración de la hegemonía neoliberal. Como planteaba el Banco Interamericano de Desarrollo, "hay un país que comenzó antes y que está hasta hoy día dando el ejemplo y sirviendo de modelo: Chile" (Espínola y Moura, 1999, p. XI). Desde entonces, los proyectos contrahegemónicos empezarán una larga historia de reconstrucción desde las bases.

\section{CONSIDERACIONES FINALES: ALGUNOS APRENDIZAJES HISTÓRICOS PARA PENSAR UN PROYECTO CONTRAHEGEMÓNICO EN EDUCACIÓN}

A principios del siglo XXI se ha consolidado el proyecto neoliberalizante, actualizando algunos de sus presupuestos en el campo educativo. En efecto, diferentes reformas educativas globales, regionales y nacionales han sido guiadas por la imitación de lógicas empresariales y bajo los lineamientos de la Nueva Gestión 
Pública (Falabella, 2015; Ruiz, Reyes y Herrera, 2018). Estas políticas han sido inadvertidamente reforzadas, tanto en el "Norte" (por ejemplo, en Estados Unidos) como en el "Sur" (por ejemplo, Brasil de Bolsonaro) como consecuencia del avance de propuestas neoconservadoras (Giroux, 2013; Apple, 2018). En la práctica, la nueva formulación del discurso educacional hegemónico propende a la asunción de un paradigma "managerialista", que responsabiliza al sujeto por sus resultados educativos y el rendimiento de los mismos en la definición de su posición social.

Es frente a la configuración de este nuevo paradigma educativo que podrían ser considerados - acaso a modo de aprendizaje o acompañamiento histórico algunos ejes problemáticos que articularon la pugna por la hegemonía durante el siglo XX. Entre otros, estos perfilan posibilidades para una mayor justicia educativa en las condiciones del siglo XXI. Dentro de estos, tres nos parecen, sin resultar para nada excluyentes, de particular relevancia:

- La posibilidad de la transformación social desde la educación: Mientras los movimientos de comienzos del siglo XX tuvieron una confianza en torno a las facultades de la educación para generar el cambio social, las perspectivas reproduccionistas proporcionaron un panorama sombrío al respecto. Como revisamos, en la experiencia histórica de la Unidad Popular la pregnancia de tales lógicas interpretativas actuaron, en alguna medida, en un sentido inmovilizante, aun cuando se presentaba la oportunidad de ensayar dicha transformación con total apoyo del gobierno y de parte importante de la sociedad. El rescate de la dimensión agencial desarrollado por la pedagogía crítica y de precursores como Paulo Freire, proporcionó nuevas esperanzas respecto del potencial transformador de la educación, cuestión asumida por los educadores populares en Latinoamérica. En la actualidad, las alternativas educativas contrahegemónicas deben decidir qué rol cabe a la educación en la modificación del orden social, bajo el entendido que la agencialidad de los actores educativos es una dimensión ineludible en dicha tarea;

- El saber legítimo en el campo educativo: La reivindicación de la educación como coadyuvante de la transformación social supone una interrogante sobre qué tipo de saber - y por tanto qué intereses y quién- es el que debería primar en la definición de la política en este campo. En el fondo, en todo proceso educativo existe un denodado esfuerzo por hacer de determinados conocimientos, saberes legítimos. Estos, además de tener un nivel instruccional, vehiculan formas de comprensión de la sociedad, de los valores sociales predominantes y del lugar de cada educando en tal orden. En el origen de los sistemas de educación estatal-nacionales, los intereses político-culturales de las elites fueron definitorios. Sin embargo, la disputa por el saber legítimo se instaló rápidamente, como lo demuestra la acción de los pedagogos de la Escuela Nueva en el "Norte" y la redefinición de sus presupuestos en clave "revolucionaria" realizada en el "Sur". Esta reivindicación del saber propiamente pedagógico fue nuevamente subordinada al promediar el siglo XX. El acicate económico y las pretensiones de "ingeniería social" 
por parte del Estado proporcionaron a los cientistas sociales el escenario para su asunción como "expertos en educación". En adelante, los actores educativos disputarán nuevamente dicha legitimidad, sin embargo, el peso del "saber científico" - en su triple vertiente: económica, sociológica y psicológica - ha sido el que ha conducido la política oficial de los Estados en las últimas décadas. Su apelación al individuo universal como centro del proceso educacional ha facilitado su asunción como "conocimiento oficial", en la medida que elude la pregunta misma por la "regionalidad" de todo saber. Abrir esta pregunta, implica incorporar la dimensión conflictiva del conocimiento escolar, sus modos de definición y la necesidad de su contextualización, particularmente en el caso de los países del "Sur";

- Sobre las relaciones entre la educación, los movimientos sociales y el Estado: Las propuestas sociales contrahegemónicas tuvieron diferentes modos de relación con el Estado. El movimiento pedagógico de la década de 1920 logró irrumpir en el campo político con un proyecto autónomo y basado en el "saber" de sus miembros. Se abrieron desde abajo y a la fuerza a los principales cauces políticos para la proyección de modelos alternativos. Con todo, fue prontamente defenestrado desde el mismo Estado que pretendían ocupar. Durante el gobierno de la Unidad popular, el mundo social, esta vez en relación estrecha con el político, intentó implementar "reformas estructurales" que chocaron con, precisamente, la "estructura" existente, la que resultó triunfante (mediante el terrorismo de Estado). Finalmente, durante la década de 1980 se desarrollaron iniciativas de "educación popular" que impugnaban de raíz a la escuela formal, pero que decayeron por la relegitimación de la acción del Estado en un contexto de tránsito formal hacia la democracia. Por ello, en la actualidad, pensar una educación más justa, de liberación e igualitaria supone reflexionar sobre el lugar del sistema educativo formal y sus relaciones con otras formas educativas, al tiempo que un esfuerzo por articular una movimentalidad social con capacidad de incidencia en la definición de tal sistema, sus objetivos y procedimientos.

Finalmente, y junto a estos tres ejes problemáticos, en la actualidad se debe reconocer la pluralización tanto de las demandas como de los actores involucrados en la disputa por la hegemonía educativa (McLaren y Kincheloe, 2008). En efecto, si durante el siglo XX el discurso pedagógico contrahegemónico se nucleó en torno a la noción de "clase" como el actor central de la transformación educativa y social, en la actualidad dicho actor, aunque nunca abandonado, ha sido acompañado o complejizado por la acción y la visibilización de nuevos sujetos con potencial emancipatorio, como las mujeres, los pueblos originarios, los mismos estudiantes u otros. De allí la importancia que han ido adquiriendo nuevos abordajes teórico-políticos (como el feminismo, el ecologismo, la decolonialidad, entre otros) para enfrentar la disputa por la hegemonía en el campo educativo en las condiciones actuales de su producción. 


\section{BIBLIOGRAFÍA}

ALLENDE. S. Panorama de la educación chilena a través del mensaje del Presidente al Congreso. Revista de Educación, Santiago de Chile, n. 39, p. 27-39, mayo 1972. ALTHUSSER,L.Ideologíay aparatos ideológicos del Estado. Bogotá: Tupac Amaru, 1974. APPLE, M. Ideology and curriculum. Londres: Routledge and Kegan Paul, 1979. APPLE, M, ¿Puede la educación cambiarla sociedad? Santiago de Chile: LOM, 2018. ASTORGA, M. Caracterización y proceso de la reforma educacional del gobierno popular. Revista de Educación, Santiago de Chile, n. 32-33, p. 2-4, nov./dic. 1970.

BARCO, S. Antididáctica o Nueva Didáctica. Revista de Ciencias de la Educación, n. 10, p. 35-58, 1973.

BARONNET, B. La educación zapatista como base de la autonomía en el sureste mexicano. Educação \& Realidade, v. 40, n. 3, p. 705-723, 2015. https://doi. org/10.1590/2175-623645794

BAUDELOT, C.; ESTABLET, R. La escuela capitalista en Francia. España: Siglo XXI, 1976.

BERNSTEIN, B. Clases, códigos y control. Madrid: Akal, 1989. v. 1.

BERNSTEIN, B. Pedagogía, control simbólico e identidad. Madrid: Morata, 1996. BONAL, X. Sociología de la educación: una aproximación crítica a las corrientes contemporáneas. Barcelona: Paidós, 1998.

BOURDIEU, P.; PASSERON, J. C. La reproducción: elementos para una teoría del sistema de enseñanza. Barcelona: Laia, 1995.

BOWLES, S.; GINTIS, H. Schooling in capitalist America. Nueva York: Basic Books, 1976. BRASTER, S.; GROSVENOR, I.; DEL POZO, M. The black box of schooling: a cultural history of the classroom. Brussels: Peter Lang, 2011.

BRUNO-JOFRÉ, R. Educación popular en América Latina durante la década de los setenta y ochenta: una cartografía de sus significados políticos y pedagógicos. Foro de Educación, v. 14, n. 20, p. 429-451, 2016. http://dx.doi.org/10.14516/ fde.2016.014.020.021

CARLI, S. Infancia y sociedad. La mediación de las asociaciones, centros y sociedades populares de educación. In: PUIGGRÓS, A. (org.). Historia de la educación argentina II: sociedad civil y Estado en los orígenes del sistema educativo argentino. Buenos Aires: Galerna, 1991. p. 13-46.

CONCHA, I. Hasta donde la reforma no ha llegado. Revista de Educación, Santiago de Chile, n. 40, p. 67-69, jun. 1971.

DA SILVA, T. Documentos de identidad: una introducción a las teorías del currículum. Belo Horizonte: Autentica, 1999.

DEPAEPE, M. Tráfico unidireccional belga y la educación colonial y el Congo: una historia de discursos simples y efectos complejos. In: HERNÁNDEZ, J.M. (coord.). Influencias belgas en la educación española e iberoamericana. Salamanca: Ediciones Universidad de Salamanca, 2019. p. 81-106. 
DEPAEPE, M.; SIMON, F. Is there any place for the history of "education" in the "history of education"? A plea for the history of everyday educational reality inand outside schools. Paedagogica Historica, v. 31, n. 1, p. 9-16, 1995. https://doi. org/10.1080/0030923950310101

DERRIDA, J. La estructura, el signo y el juego en el discurso de las ciencias humanas. In: DERRIDA, J. La escritura y la diferencia. Barcelona: Anthopos, 1989. p. 383-401. DONOSO-ROMO, A.; CONTRERAS-MÜHLENBROCK, R. La dimensión social del movimiento estudiantil de Córdoba en 1918. Izquierdas, n. 33, p. 42-65, 2017. http://dx.doi.org/10.4067/S0718-50492017000200042

DOSSE, F. Historia del estructuralismo. Madrid: Akal, 2004. v. 2.

DUBET, F. Repensar la justicia social: contra el mito de la igualdad de oportunidades. Madrid: Siglo XXI, 2011.

DURKHEIM, E. Educación como socialización. Salamanca: Ediciones Sígueme, 1976. ESPÍNOLA, V.; MOURA, C. (eds.). Economía política de la reforma educacional en Chile: la reforma vista por sus protagonistas. Washington, D.C.: BID, 1999.

FALABELLA, A. El mercado escolar en Chile y el surgimiento de la nueva gestión pública: el tejido de la política entre la dictadura neoliberal y los gobiernos de la centroizquierda (1979 a 2009). Educação \& Sociedade, v. 36, n. 132, p. 699-722, 2015. https://doi.org/10.1590/ES0101-73302015152420

FARRELL, J. The national unified school in Allende's Chile: the role of education in the destruction of a revolution. Vancouver: University of British Columbia Press, 1986. FERNÁNDEZ ENGUITA, M. Integrar o segregar. Barcelona: Laia, 1989.

FERRER, F. La escuela moderna. Barcelona: E1 Viejo Topo, 2014.

FERRIÈRE, A. La Educación Nueva en Chile (1928-1939). Madrid: Bruno del Amo Editor, 1932.

FOUCAULT, M. Defender la sociedad: curso en el Còllege de France (1975-1976). Buenos Aires: Fondo de Cultura Económica, 1997.

FREIRE, P. Pedagogía del oprimido. Montevideo: Tierra Nueva, 1970.

FREIRE, P. Entrevista con Paulo Freire. In: TORRES, C.A. (org.). Educación, podery biografía: diálogos con educadores críticos. Ciudad de México: Siglo XXI, 2004.p. 93-107. GARCÍA-HUIDOBRO, J.; MARTINIC, S. Educación popular en Chile: algunas proposiciones básicas. Santiago: CIDE, 1980.

GEERTZ, C. La interpretación de las culturas. Barcelona: Gedisa, 2003.

GIROUX, H. Theories of reproduction and resistance in the new sociology of education: a critical analysis. Harvard Educational Review, v. 53, n. 3, p. 257-293, 1983. https:// doi.org/10.17763/haer.53.3.a67x4u33g7682734

GIROUX, H. Teoría y resistencia en educación: una pedagogía para la oposición. México: Siglo XXI, 2004.

GIROUX, H. La pedagogía crítica en tiempos oscuros. Praxis Educativa, v. 17, n. 2, p. 13-26, 2013. 
GONZÁLEZ,M. Una aproximación historiográfica sobre el origen de los estudios de la «caja negra». Las investigaciones del aula desde la historia de la educación en Gran Bretaña y EEUU. Profesorado, v. 17, n. 3, p. 389-408, 2013.

ILLICH, I. Deschooling society. Nueva York: Harper \& Row, 1971.

JACKSON, P. La vida en las aulas. Madrid: Morata, 1992.

JARA, O. La educación popular latinoamericana: historia y claves éticas, políticas y pedagógicas. Santiago: Quimantú, 2020.

LACEY, C. Hightown grammar: the school as a social system. Manchester: Manchester University Press, 1970.

LAGOS, M. Experiencias educativas y prácticas culturales anarquistas en Chile (1890-1927). Santiago: Quimantú, 2013.

LEYTON, M. Planeamiento educacional: principios básicos del currículum y del aprendizaje, un modelo pedagógico del planeamiento educacional. Santiago: Editorial Universitaria, 1975.

MARIÁTEGUI, J. La crisis de reforma educacional en Chile. Mundial, Lima, 1929. MCLAREN, P. La vida en las escuelas: una introducción a la pedagogía crítica en los fundamentos de la educación. México: Siglo XXI, 1984.

MCLAREN, P.; KINCHELOE, J. L. (coord.). Pedagogía crítica: de qué hablamos, dónde estamos. España: Graó, 2008.

MEJÍA, R. La educación popular: una construcción colectiva desde el Sur y desde abajo. Archivos Analíticos de Políticas Educativas, v. 22, n. 62, p. 1-35, 2014. http://dx.doi. org/10.14507/epaa.v22n62.2014

MINISTERIO DE EDUCACIÓN. Segundo Aporte del Ministerio de Educación a sus Debates. Congreso Nacional de Educación. Revista de Educación, Santiago de Chile, n. 36, p. 71-98, 1971a.

MINISTERIO DE EDUCACIÓN. Temario de los congresos provinciales y nacionales de educación. Revista de Educación, Santiago de Chile, n. 35, p. 172178, abr. $1971 \mathrm{~b}$.

MÜLLER, D.; RINGER, F.; SIMON, B. The rise of the modern educational system: structural change and social reproduction 1870-1920. Londres y Nueva York: Cambridge University Press, 1987.

NEUT AGUAYO, P.; NEUT AGUAYO, S.; NEUT AGUAYO, M. Seguridad para estudiar, libertad para vivir": una aproximación histórica al movimiento secundario chileno en dictadura a partir de la experiencia del liceo de aplicación. Izquierdas, n. 49, p. 2178-2212, 2020.

NEUT AGUAYO, S. Prácticas y discurso intelectual en ONG's educacionales opositoras a la Dictadura chilena. Los casos del CIDE y PIIE. Izquierdas, n. 42, p. 198-223, 2018. http://dx.doi.org/10.4067/S0718-50492018000500198

NEWLAND, C. The estado docente and its expansion: Spanish American elementary education, 1900-1950. Journal of Latin American Studies, v. 26, n. 2, p. 449-467, 1994. https://doi.org/10.1017/S0022216X00016291 
NÚÑEZ, I. Reformas educacionales e identidad de los docentes: Chile, 1960-1973. Santiago: PIIE, 1990.

NÚÑEZ, I. Política y educación. Rol, fines y objetivos de la educación en un gobierno popular. Revista de Educación, Santiago de Chile, n. 32-33, p. 8-10, nov./dic. 1970. NÚÑEZ, I. Notas sobre educación y fuerzas armadas. Signos, v. 4, p. 34-40, 1984. NÚÑEZ, I. El trabajo docente: dos propuestas históricas. Santiago: PIIE, 1987. OLIVA, M. A. Política educativa chilena 1965-2009. ¿Qué oculta esa trama? Revista Brasileira de Educação, v. 15, n. 44, p. 311-328, 2010. https://doi.org/10.1590/S141324782010000200008

POPKEWITZ,T. Sociología política de las reformas educativas. Madrid: Morata, 1994. POPKEWITZ, T. (ed.). Inventing the modern self and John Dewey: Modernities and the traveling of pragmatism in education. Nueva York: Palgrave Macmillan Press, 2005. PUIGGRÓS, A. Imperialismo y educación en América Latina. Argentina: Ediciones Colihue, 2015.

PUIGGRÓS, A. La educación popular en América Latina: orígenes, polémicas y perspectivas. Argentina: Ediciones Colihue, 2016.

RANCIÈRE, J. La noche de los proletarios. Buenos Aires: Tinta Limón, 2010.

REYES, L. La escuela en nuestras manos. Santiago: Quimantú, 2014.

REYES-JEDLICKI, L. The crisis of the Estado docente and the critical education movement: the Escuelas Obreras Federales Racionalistas in Chile (1921-1926).Journal of Latin American studies, v. 39, n. 4, p. 827-855, 2007. http://dx.doi.org/10.1017/ S0022216X07003240

RUIZ, C.; REYES, L.; HERRERA, F. (eds.). Privatización de lo público en el sistema escolar: Chile y la agenda global de educación. Santiago: LOM, 2018.

SEIA, G. El movimiento estudiantil contra la política universitaria de la última dictadura en Argentina. El caso de la Universidad de Buenos Aires. Izquierdas, n. 49, p. 2213-2247, 2020.

SUÁREZ, W. Democracia y Educación. Aportes en torno a la democratización de la educación chilena. Revista de Educación, Santiago de Chile, n. 32-33, p. 5-7, 1970.

SUASNÁBAR, C.Intelectuales, exilios y educación: producción intelectual e innovaciones teóricas en educación durante la última dictadura. Buenos Aires: Prohistoria, 2013.

VASCONI, T. Contra la escuela, borradores para una crítica marxista de la educación. Revista de Ciencias de la Educación, v. 9, p. 5-24, 1973.

VIÑAO, A. Sistemas educativos, culturas escolares y reformas: continuidades y cambios. Madrid: Morata, 2006.

WILLIAMS, R. La larga revolución. Buenos Aires: Nueva Visión, 2003.

WILLIS, P. Learning to labour: how working class kids get working class jobs. Sussex: Saxon House, 1977.

YOUNG, M. Knowledge and control: new directions for the sociology of education. Londres: Collier MacMillan, 1971. 


\section{SOBRE LOS AUTORES}

Sebastián Neut Aguayo es doctorando en Educación en la Katholieke Universiteit Leuven (Bélgica). Codirector Editorial Sole (Chile). E-mail:sgneut@uc.cl

Pablo Neut Aguayo es doctorando en Educación en la Universidad de Barcelona (España). Miembro del Núcleo Milenio Autoridad y Asimetrías de Poder. Codirector Editorial Sole (Chile).

E-mail: paneut@uc.cl

Conflictos de interés: Los autores no poseen ningún interés comercial o asociativo que represente un conflicto de interés con relación al manuscrito.

Financiamiento: Los autores son becarios de Becas de Doctorado en el Extranjero, Agencia Nacional de Investigación y Desarrollo de Chile.

Contribuciones de los autores: Análisis Formal, Conceptualización, Redacción - Primera Redacción, Redacción — Revisión y Edición, Investigación: Neut, S.; Neut, P. 